\title{
Compound A, a Dissociated Glucocorticoid Receptor Modulator, Inhibits T-bet (Th1) and Induces GATA-3 (Th2) Activity in Immune Cells
}

\author{
Ana C. Liberman ${ }^{19}$, Maria Antunica-Noguerol ${ }^{19}$, Viviane Ferraz-de-Paula ${ }^{2}$, Joao Palermo-Neto ${ }^{2}$, \\ Carla N. Castro', Jimena Druker ${ }^{1}$, Florian Holsboer ${ }^{3}$, Marcelo J. Perone', Sarah Gerlo ${ }^{4,5}$, Karolien De \\ Bosscher ${ }^{4,5}$, Guy Haegeman ${ }^{4}$, Eduardo Arzt ${ }^{1,3 *}$
}

1 Laboratorio de Fisiología y Biología Molecular, Departamento de Fisiología y Biología Molecular y Celular, Facultad de Ciencias Exactas y Naturales, Universidad de Buenos Aires and Instituto de Investigación Biomedicina de Buenos Aires (IBioBA)-CONICET-Partner Institute of the Max Planck Society, Buenos Aires, Argentina, 2 Neuroimmunomodulation Research Group, FMVZ-USP, San Pablo, Brasil, 3 Max Planck Institute of Psychiatry, Munich, Germany, 4 Laboratory for Eukaryotic Gene Expression and Signal Transduction, Ghent University, Ghent, Belgium, 5 VIB Department of Medical Protein Research, UGent, Ghent, Belgium

\begin{abstract}
Background: Compound $\mathrm{A}(\mathrm{CpdA})$ is a dissociating non-steroidal glucocorticoid receptor (GR) ligand which has antiinflammatory properties exerted by down-modulating proinflammatory gene expression. By favouring GR monomer formation, CpdA does not enhance glucocorticoid (GC) response element-driven gene expression, resulting in a reduced side effect profile as compared to GCs. Considering the importance of Th1/Th2 balance in the final outcome of immune and inflammatory responses, we analyzed how selective GR modulation differentially regulates the activity of T-bet and GATA-3, master drivers of Th1 and Th2 differentiation, respectively.
\end{abstract}

Results: Using Western analysis and reporter gene assays, we show in murine T cells that, similar to GCs, CpdA inhibits T-bet activity via a transrepressive mechanism. Different from GCs, CpdA induces GATA-3 activity by p38 MAPK-induction of GATA-3 phosphorylation and nuclear translocation. CpdA effects are reversed by the GR antagonist RU38486, proving the involvement of GR in these actions. ELISA assays demonstrate that modulation of T-bet and GATA-3 impacts on cytokine production shown by a decrease in IFN- $\gamma$ and an increase in IL-5 production, respectively.

Conclusions: Taken together, through their effect favoring Th2 over Th1 responses, particular dissociated GR ligands, for which CpdA represents a paradigm, hold potential for the application in Th1-mediated immune disorders.

Citation: Liberman AC, Antunica-Noguerol M, Ferraz-de-Paula V, Palermo-Neto J, Castro CN, et al. (2012) Compound A, a Dissociated Glucocorticoid Receptor Modulator, Inhibits T-bet (Th1) and Induces GATA-3 (Th2) Activity in Immune Cells. PLoS ONE 7(4): e35155. doi:10.1371/journal.pone.0035155

Editor: Alice Y. W. Chang, Kaohsiung Chang Gung Memorial Hospital, Taiwan

Received November 21, 2011; Accepted March 9, 2012; Published April 9, 2012

Copyright: (c) 2012 Liberman et al. This is an open-access article distributed under the terms of the Creative Commons Attribution License, which permits unrestricted use, distribution, and reproduction in any medium, provided the original author and source are credited.

Funding: This work was supported by Grants from the Max Planck Society, Germany; the University of Buenos Aires (UBA), the CONICET and Agencia Nacional de Promoción Científica y Tecnológica, Argentina; and the bilateral program of FWO Vlaanderen. The funders had no role in study design, data collection and analysis, decision to publish, or preparation of the manuscript.

Competing Interests: The authors have declared that no competing interests exist.

* E-mail: earzt@fbmc.fcen.uba.ar

9 These authors contributed equally to this work.

\section{Introduction}

Glucocorticoids (GCs) are the most potent and frequently used anti-inflammatory drugs for a variety of Th1- and Th2-mediated immune disorders. Nevertheless, long-term applications are often complicated by severe adverse effects [1]. GCs act via binding to the glucocorticoid receptor (GR), a transcription factor (TF) belonging to the nuclear receptor superfamily. It is widely accepted that the desired anti-inflammatory effects of GCs are caused by the interaction of the monomeric GR with the activity of other TFs that drive proinflammatory gene expression, whereas the direct binding of GR to GC response elements (GREs) resulting in the direct transcription of target genes is mostly associated with well-known endocrine side effects [2]. This has led to the search for selective GR modulators, such as dissociated GR ligands, that selectively transrepress and which are predicted to reduce the appearance of a wide range of side effects. As the quest for dissociated steroidal GR ligands did not quite live up to expectations, there is currently a renewed interest of the pharmaceutical industry to find non-steroidal selective GR modulators with a reduced side effect profile yet maintaining their therapeutic efficacy [3].

Compound A $(\mathrm{Cpd} A)$ is a stable analog of the hydroxy phenyl aziridine precursor found in the Namibian shrub Salsola tuberculatiformis Botschantzev [4]. CpdA is a clearly dissociating compound [4]. This means that it does not stimulate GRE-driven gene expression. It has been shown that $\mathrm{CpdA}$ and the synthetic GC dexamethasone (Dex) interact with the GR with comparable affinities, in the nanomolar range, but varying dependent on the cell type [4,5]. The specific gene-repressive effect of CpdA depends on the presence of functional monomeric GR [6], displaying a differential phosphorylation status as compared to 
Dex [4]. The anti-inflammatory mechanism of CpdA involves both a reduction of DNA-binding activity, as well as an interference with the transactivation potential of NF- $\mathrm{B}$ [4], which plays a central role in inflammation. Analysis of diverse mouse models of inflammatory and autoimmune diseases further supports the idea that $\mathrm{CpdA}$ has a potent anti-inflammatory activity and particularly lacks diabetogenic and bone metabolism side effects when applied in vivo compared with GCs [4,6-10].

The adaptive immune response is triggered when $\mathrm{T}$ cells recognize antigens, which have been presented by antigen presenting cells. GATA-3 [11] is a master TF involved in Th2 development [12]. Th2 cytokines promote B cell-mediated humoral immunity against extracellular pathogens [13]. Th2 cytokines include IL-4, IL-5, IL-13 and IL-10. Ectopic expression of GATA-3 in developing and fully committed Thl cells gives rise to Th2 cytokine production as well as Th1 cytokine inhibition [14]. GATA-3 regulates Th2 cytokine expression not only at the transcription level, by directly binding to the IL-5-promoter, but also by remodeling the chromatin structure and opening the IL-4 locus [15]. As a master control, GATA-3 stabilizes the Th2 phenotype in three ways [16]. First, GATA-3 shuts down Th1 development by down-regulation of STAT4/IL-12Rbeta2 chain or T-bet. Second, GATA-3 augments its own expression by a positive feedback autoregulation [17]. Third, GATA-3 favors selective growth of Th2 cells [16]. In Th2 cells [18], cAMP induces GATA-3 phosphorylation via p38 MAPK and stimulates GATA3 -dependent promoter activities [18,19]. Intracellular increments of cAMP levels in Th cells are associated with an augmentation of Th2 cytokine production via GATA-3 and protein kinase A (PKA) activation [20].

$\mathrm{T}$ box expressed in $\mathrm{T}$ cells (T-bet) is a Thl specific TF that controls the expression of the potent proinflammatory cytokine IFN-gamma (IFN- $\gamma)$ [21], hallmark of Thl cell-mediated immunity [22,23]. Over-expression of T-bet into primary $\mathrm{T}$ cells or even fully polarized Th2 cells is able to generate IFN- $\gamma$-producing Th1 cells, concomitant with an inhibition of the production of the Th2 cytokines IL-4 and IL-5 [21]. T-bet deficient mice show normal lymphoid development, but profound defects in mounting a Th1 immune response and a corresponding increase in Th2 cytokines [24]. T-bet may down-regulate GATA-3 function either by regulating its expression or by inhibiting its activity $[21,25]$.

We have previously described that GGs inhibit the transcriptional activity of T-bet [26] by a transrepression mechanism involving a protein-protein interaction between the activated GR and T-bet, resulting in a diminished DNA binding [26]. Also the master Th2 TF GATA-3 is inhibited by GCs, yet via a different molecular mechanism. GCs inhibit GATA-3 activity by the inhibition of p38 MAPK-induced GATA-3 phosphorylation and its nuclear translocation $[27,28]$. Therefore, by suppressing Thl responses to a stronger extent than Th2, GCs favor a shift from a Th1 towards a Th2 profile, which might have relevant implications in the treatment of Th1-polarized immune disorders $[26,29]$.

In order to discover novel targets in relevant immunemodulatory pathways that may be differentially affected by nonconventional GR modulators such as CpdA, and hence may become of direct clinical relevance, a detailed understanding of the molecular mechanism underlying the immune-modulatory effects of GCs and dissociated GCs in immune cells is a prerequisite. Although recent data regarding the effect of CpdA on the expression of Th cytokines in various animal models of immune diseases has been presented [7,8], the molecular mechanism underlying differential effects of a selective modulation of GR in immune cells on downstream TF targets has not yet been clarified.
To this purpose, we investigated how CpdA- and Dexamethasone (Dex)-activated GR differentially affect the activity of key TFs involved in the regulation and final outcome of Th-mediated immune responses.

\section{Results}

\section{CpdA Inhibits the Transcriptional Activity of T-bet}

We established before that conventional GR activation, through the use of the classic GC Dexamethasone (Dex), can negatively impact on the activity of T-bet [26]. At present it is unknown whether or not selective GR modulation, through the use of the dissociated GR modulator $\mathrm{CpdA}$, can regulate the activity of immune-regulatory TFs, other than NF- $\mathrm{BB}$. Hence, we investigated whether CpdA could also negatively regulate the transcriptional activity of the key Thl TF T-bet. Transfection of EL4 T cells with T-bet response elements cloned upstream of the luciferase gene (T-bet-RE-Luc) together with GR (CMV-hGR) and T-bet (pcDNA3-T-bet) expression vectors in the presence of increasing amounts of CpdA led to a dose-dependent inhibition of T-bet's transcriptional activity (Fig. 1A), similar to the effect we have previously reported for GCs (Fig. 1A, striped bar) [26]. The antagonistic effect exerted by RU38486 proved that the ligandbinding domain of GR is involved in CpdA-mediated inhibition of T-bet activity (Fig. 1A). In addition, no effect of CpdA was observed when the GR was absent from the transfection experiments. Similar results were obtained using the human Jurkat $\mathrm{T}$ cell line (data not shown).

Western Blot assays performed under similar conditions as mentioned above, showed that CpdA does not affect the overexpressed protein levels of T-bet (Fig. 1B), strongly suggesting that CpdA directly targets T-bet at the transcriptional level.

\section{CpdA Inhibits the Transcriptional Activity of T-bet via a Transrepression Mechanism}

Taking into account that GCs inhibit T-bet activity via transrepression and that CpdA does not transactivate GREdependent genes but can transrepress cytokine genes [4], we analyzed whether the underpinning mechanism by which CpdA inhibits T-bet activity could be transrepression. To adress this hypothesis we used two extensively described GR mutants [26,30,31]. A458T is a D-loop dimerization interface mutation that blocks GR dimerization and activation of transcription [31]. S425G is a DBD mutant that has a serine to glycine substitution at position 425, which removes a hydroxyl group supposed to alter bondings between the zinc finger domain and other proteins and hence disrupts transrepression [30]. Transfection and recombinant reporter gene analyses in EL4 cells show that CpdA-activated wild-type GR, but not CpdA-activated S425G GR, the GR mutant defective for transrepression, was able to transrepress $\kappa \mathrm{B}-$ Luc activity (Fig. 2A). On the contrary, CpdA retained its transrepressive capacity when triggering the A458T GR-transactivation defective mutant (Fig. 2A). Neither the wild-type nor the mutant GRs could transactivate TK-GRE2-Luc in the presence of CpdA (Fig. 2B), confirming its dissociated activity also in immune cells. As expected, Dex, the classic GC, behaved similar as CpdA in the transrepression assays (Fig. 2A, striped bars), and opposite to $\mathrm{CpdA}$ in the transactivation assays (Fig. 2B, striped bars).

Concerning the effect of a dissociative GR modulation on the T-bet-RE-Luc reporter gene activity, we found that both CpdAactivated wild-type GR and A458T, the GR-transactivation mutant, can strongly inhibit T-bet activity. On the contrary, CpdA-activated S425G GR mutant displayed a reduced ability in repressing T-bet activity, when compared to the strong inhibition 

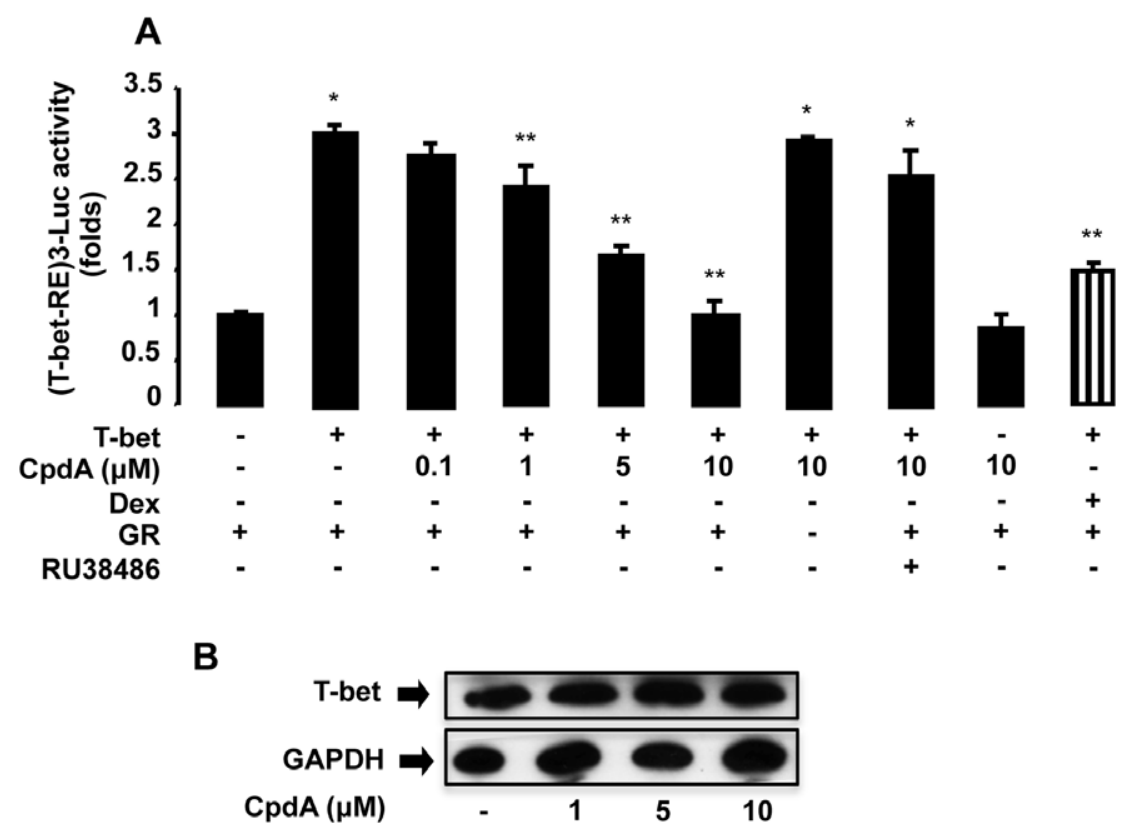

Figure 1. Compound A inhibits T-bet transcriptional activity. A, EL4 cells were transfected with $9 \mu \mathrm{g}$ of a reporter plasmid which contains Tbet response elements upstream of the luciferase gene (T-bet-RE-Luc) with or without $9 \mu \mathrm{g}$ of T-bet and GR expression vectors. After $16 \mathrm{~h}$ in culture, cells were stimulated for $5 \mathrm{~h}$ with or without Compound $\mathrm{A}(\mathrm{CpdA}, 0.1,1,5$ and $10 \mu \mathrm{M})$, Dexamethasone (Dex, $10 \mathrm{nM}$ ) or the GR specific antagonist RU38486 $(1 \mu \mathrm{M})$. Results, as folds, normalized to $\beta$-galactosidase activity, are expressed as mean \pm SEM $\left(n=6,{ }^{*} p<0.001\right.$ vs. basal without T-bet, ** $p<0.05$ vs. T-bet without (pdA), averaged from three independent experiments. $B$, Lysates obtained from transfection experiments performed under similar conditions as mentioned above, were prepared for T-bet analysis by Western Blot. Single bands corresponding to T-bet were obtained. GAPDH signal was used as loading control; one of three independent experiments with similar results is shown.

doi:10.1371/journal.pone.0035155.g001

exerted by the CpdA-treated wild-type and A458T mutant. These data, using mutant GR and/or the dissociative activity of a GR ligand, are in line with a mechanism whereby the transrepressive function of GR can be exclusively held responsible for the GRmediated inhibition of T-bet activity.

\section{CpdA Inhibits T-bet-driven IFN- $\gamma$ Gene Expression and Protein Production}

We tested the functional relevance of CpdA-mediated inhibition of T-bet transcriptional activity on IFN- $\gamma$, hallmark of Th1mediated immune responses [21]. To investigate whether CpdAdependent inhibition of T-bet activity can be observed in a functionally relevant promoter context, i.e. on the IFN- $\gamma$ promoter, EL4 cells were transfected with a $-3447-\mathrm{IFN}-\gamma$ promoter cloned upstream of the luciferase gene together with the GR expression vector. Over-expression of T-bet resulted in a strong increase of the luciferase activity, whilst cotransfection of GR in the presence of CpdA led to the inhibition of IFN- $\gamma$ promoter activity (Fig. 3A). No effect of CpdA was observed when GR was absent from the transfection experiments. Under the same conditions as in the transfection experiments, Western Blots were carried out to analyze T-bet protein expresion. No changes in the over-expressed T-bet protein levels were observed following CpdA treatment (data not shown), suggesting that the CpdA-mediated inhibition of T-bet is at the transcriptional level and a relevant mechanism in the regulation of the IFN- $\gamma$ promoter. Next, we analyzed whether the transcriptional repression of CpdA could also be reflected in a diminished IFN- $\gamma$ protein production in purified CD4+ T cell cultures. Indeed, Fig. 3B shows that CpdA strongly inhibits IFN- $\gamma$ production. Similar results were obtained in non-adherent and in total splenocyte cultures (data not shown).
CpdA Induces the Transcriptional Activity of GATA-3 by Signaling Through p38 MAPK

To determine whether CpdA also regulates the transcriptional activity of the master Th2 TF GATA-3, we transfected EL4 cells with a GATA-3-dependent reporter gene construct (GATA-3-RELuc) together with GR (GMV-hGR) and GATA-3 (pcDNA3GATA-3) expression vectors (Fig. 4A). Contrary to the effect we have previously described for GCs [27], increasing amounts of CpdA, in the presence of cAMP, led to a dose-dependent induction of GATA-3 activity (Fig. 4A).

The reversion by the specific antagonist RU38486 proved that the ligand-binding module of the GR is involved in the CpdAmediated induction of GATA-3 activity (Fig. 4A). In addition, no effect of CpdA was observed when GR was not present in the transfection experiment. Similar results were obtained using Jurkat cells (data not shown).

As the induction of GATA-3 activity could be the consequence of an increased GATA-3 protein expression, we analyzed overexpressed GATA-3 protein levels by Western Blot under the same conditions as in the transfection experiments. We observed no changes in GATA-3 protein levels, strongly suggesting that CpdA induces GATA-3 transcriptional activity (Fig. 4B).

As previously described, cAMP treatment enhances the activity of GATA-3 via p38 MAPK induction [18-20,27]. Therefore, in order to study the effect of CpdA on the activity of this kinase, EL4 cells were transfected with a GATA-3-dependent reporter gene construct (GATA-3-RE-Luc) together with GR (GMV-hGR) and GATA-3 (pcDNA3-GATA-3) expression vectors. CpdA-induced GATA-3 activity was inhibited in the presence of the kinase inhibitor SB203580 (Fig. 4C), supporting the involvement of the p38 MAPK pathway for CpdA-induced GATA-3 activity. Overexpressing p38 MAPK, using a p38 expression vector 

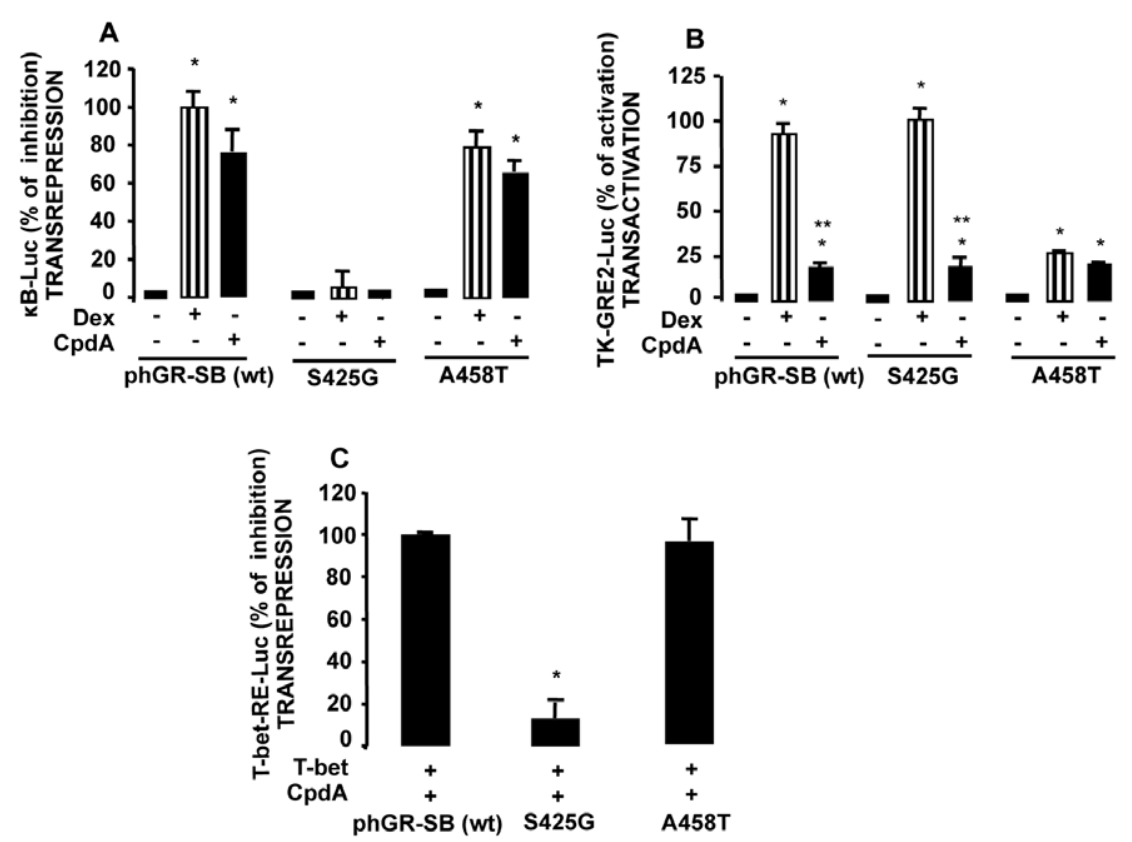

Figure 2. Compound $\mathbf{A}$ inhibits T-bet transcriptional activity by transrepression. $A$, EL4 cells were cotransfected with $9 \mu \mathrm{g}$ of $\kappa B$-Luc reporter plasmid and $9 \mu \mathrm{g}$ of Rel A plus $9 \mu \mathrm{g}$ of phGR-SB (wt) wild-type GR expression vectors or the GR mutants A458T or S425G. After $16 \mathrm{~h}$, cells were stimulated for $8 \mathrm{~h}$ with IL-1 $\beta(10 \mathrm{ng} / \mathrm{ml})$, which induces $\kappa B$-Luc activity, and with CpdA $(10 \mu \mathrm{M})$ or Dex $(100 \mathrm{nM})$. Results, as \% of inhibition of KB-Luc, normalized to $\beta$-galactosidase activity, are expressed as mean \pm SEM ( $n=3,{ }^{*} p<0.001$ vs. Rel A plus IL-1 $\beta$ without Dex or CpdA), of one representative experiment of three independent experiments with similar results. $B$, EL4 cells were transfected with $9 \mu \mathrm{g}$ of a reporter plasmid containing two palindromic GR-binding sites coupled to the TK promoter reporter plasmid (TK-GRE2-Luc) plus $9 \mu \mathrm{g}$ of phGR-SB (wt) wild-type GR expression vector or the GR mutants A458T or S425G. After $16 \mathrm{~h}$, cells were stimulated for $5 \mathrm{~h}$ with CpdA or Dex. Results, as \% of activation of TKGRE2-Luc, normalized to $\beta$-galactosidase activity, are expressed as mean \pm SEM $\left(n=3,{ }^{*} p<0.05\right.$ vs. basal without Dex or CpdA, ${ }^{* *} p<0.05$ vs. Dex treated wild-type or S425G mutant GR), of one representative experiment of three independent experiments with similar results. $C$, EL4 cells were transfected with $9 \mu \mathrm{g}$ of T-bet-RE-Luc reporter plasmid and with $9 \mu \mathrm{g}$ of T-bet and wild-type GR expression vectors (ph-GR-SB) or the GR mutants A458T or S425G. After $16 \mathrm{~h}$, cells were stimulated for $5 \mathrm{~h}$ with CpdA. Results, as $\%$ of inhibition of T-bet-RE-Luc, normalized to $\beta$-galactosidase activity, are expressed as mean \pm SEM ( $n=3,{ }^{*} p<0.001$ vs. ph-GR-SB or A458T-mediated T-bet-RE-Luc relative inhibition) of one representative experiment of three independent experiments with similar results. doi:10.1371/journal.pone.0035155.g002

(pcEFL-p38 $\alpha$ ), resulted in a further increase of CpdA- and cAMPinduced GATA-3 activities. These results confirm an important role for p38 MAPK in driving the activity of GATA-3, elicited by two different (Fig. 4D).

To test whether the molecular mechanism by which CpdA induces the transactivation of GATA-3 involves CpdA-mediated p38 phosphorylation, we performed Western Blot assays in EL4 cells transfected with a GR expression vector (CMV-hGR) in the presence of CpdA and cAMP (Fig. 4E). The results demonstrate that CpdA already on its own strongly induces p38 phosphorylation, and that the effect is enhanced in the presence of cAMP.

Phosphorylation and activation of the downstream TF ATF2 is known to reflect an activation of the p38 MAPK signaling pathway [32]. A chimeric trans-activator protein containing ATF2 fused to the DNA binding domain of the yeast transcriptional activator GAL4 (pFA-ATF2) was transiently transfected into cells with a luciferase reporter containing five copies of a GAL4 DNA binding element upstream of a TATA box and the luciferase gene (pG5-Luc). Thus, by monitoring the activity of the pG5-Luc reporter, the activation of ATF2 by p38 MAPK was followed. Fig. $4 \mathrm{~F}$ shows that CpdA strongly induces the reporter activity and SB203580 inhibits this induction further confirming that CpdA is able to induce p38 MAPK activity.

PKA, MEK-1 and JNK pathways are not involved as shown by the lack of inhibition of CpdA-induced GATA-3 activity using the specific inhibitors of these kinases H89, PD98059 and SP600125 respectively (data not shown).

\section{CpdA Induces Phosphorylation and Nuclear} Translocation of GATA-3

It has been reported that p38 MAPK induces GATA-3 phosphorylation and nuclear translocation, which impacts on the transcriptional activity of GATA-3 [19]. To directly investigate whether the effect of CpdA on p38-mediated GATA-3 activity involves the induction of GATA-3 phosphorylation [27,28], Western Blots were performed using EL4 cells stimulated under basal, cAMP- and CpdA-activating conditions using a specific antibody against phospho-GATA-3 (p-GATA-3). As shown in Fig. 5A, although CpdA does induce a slight GATA-3 phosphorylation on its own; in the presence of cAMP, this effect is significantly enhanced. As expected, also cAMP on its own induces phosphorylation of GATA-3. Whole extract lysates were used as controls for total GATA-3 expression (Fig. 5A).

To address whether CpdA further enhances the nuclear translocation of GATA-3, we performed Western Blot experiments using cytoplasmic and nuclear extracts. Fig. 5B shows that as previously reported, cAMP induces GATA-3 nuclear translocation. An additional treatment with CpdA further induces this translocation. A specific antibody against Histone $\mathrm{H} 3$ was used as control to demonstrate the purity of the nuclear extracts and GAPDH was used as control of the cytoplasmic extracts (Fig. 5B). 

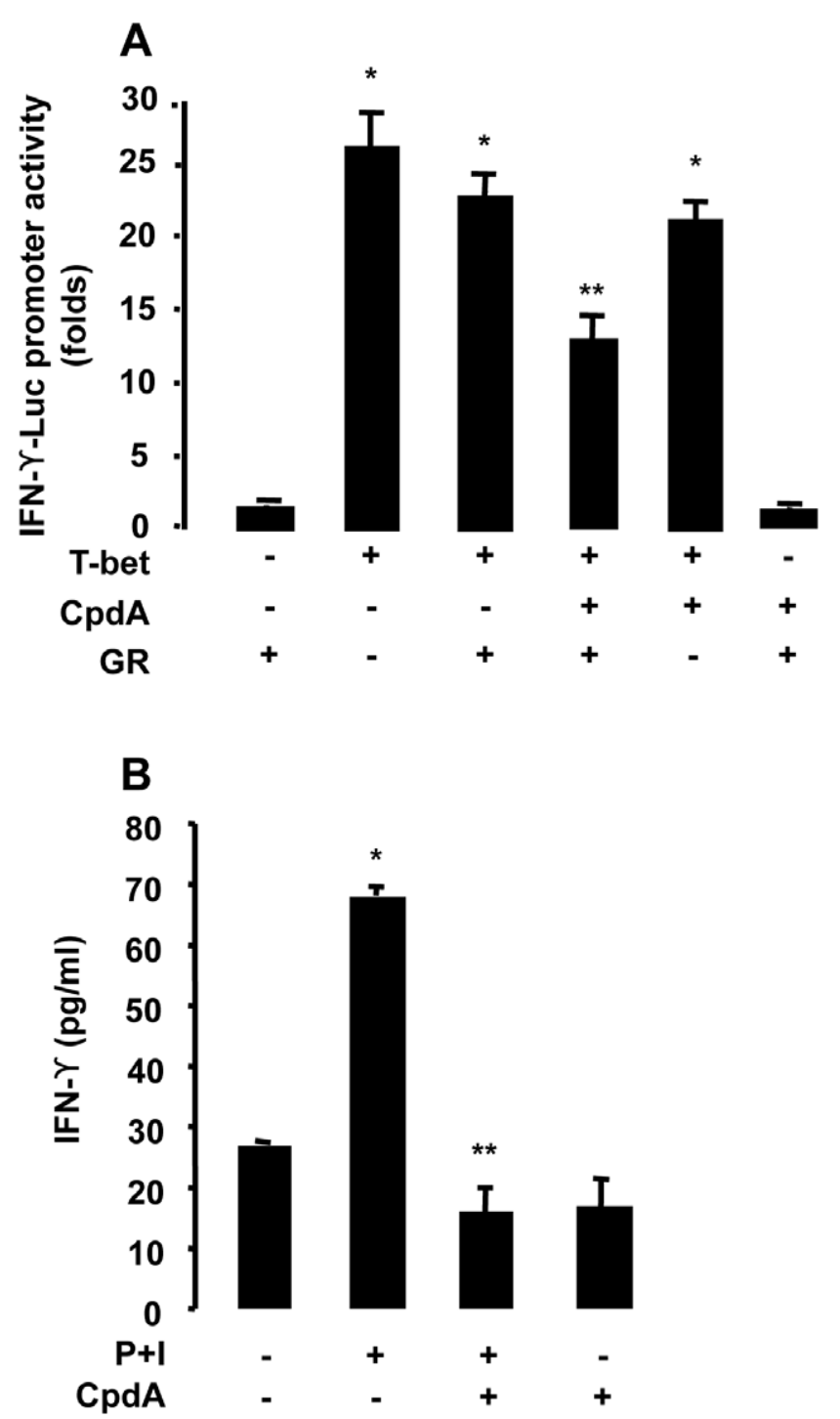

Figure 3. Compound A inhibits IFN- $\gamma$ promoter activity and cytokine production. A, EL4 cells were cotransfected with $9 \mu \mathrm{g}$ of IFN- $\gamma$ promoter-driven luciferase plasmid (IFN- $\gamma$-Luc) plus $9 \mu \mathrm{g}$ of GR expression vector and with $9 \mu \mathrm{g}$ of T-bet expression vector. After $16 \mathrm{~h}$ in culture, cells were stimulated for $5 \mathrm{~h}$ with Compound $\mathrm{A}$ (CpdA, $10 \mu \mathrm{M})$. Results, as folds, normalized to $\beta$-galactosidase activity, are expressed as mean \pm SEM $\left(n=6,{ }^{*} p<0.001\right.$ vs. basal without T-bet, ** $p<0.001$ vs. T-bet without (pdA), averaged from three independent experiments. $B$, Purification of T cells was achieved by a conventional technique involving cell adhesion to plastic and then to a nylon wool column and alternatevely by FACS sorting. Purified $T$ cells were activated with PMA (P) and lonomycin (I) during $24 \mathrm{~h}$ and then incubated with CpdA for $5 \mathrm{~h}$. Supernatants were used to measure mouse IFN- $\gamma$ according to the manufacturer's instructions by ELISA. Results are expressed as mean \pm SEM $\left(n=4,^{*} p<0.001\right.$ vs. basal without $\mathrm{CpdA}$, ${ }^{* *} \mathrm{p}<0.001$ vs. $\mathrm{P}+\mathrm{I}$ without $\mathrm{CpdA}$ ) of one representative experiment of three independent experiments with similar results. doi:10.1371/journal.pone.0035155.g003

\section{CpdA Induces GATA-3-driven IL-5 Gene Expression and Protein Production}

To investigate the possible involvement of CpdA-dependent induction of GATA-3 activity in the regulation of IL-5, a central Th2 cytokine, EL4 cells were transfected with the IL-5 promoter cloned upstream of the luciferase gene together with GR (CMV-
hGR) and GATA-3 (pcDNA3-GATA-3) expression vectors. Overexpression of GATA-3 in the presence of CpdA led to strong induction of IL-5 activity (Fig. 6A). The involvement of p38 MAPK was evident because CpdA-induced GATA-3 activity was inhibited in the presence of the specific kinase inhibitor SB203580.

To confirm the involvement of GATA-3 on CpdA-mediated IL5 promoter activity, we transfected EL4 cells with the proximal IL5 promoter $(-120$ to +44$)$ bearing its unique GATA-3 binding site (around position -72), or its mutated version on the GATA-3 binding site (IL5-Gm-luc) (Fig. 6B). CpdA induces the wild-type IL-5 promoter activity but its effect is strongly inhibited upon using the promoter variant containing the mutated GATA-3 binding site, confirming the importance of GATA-3 in mediating the CpdA-activated promoter activity.

The A20 mouse B lymphoma cell line, which does not express endogenous GATA-3 but expresses endogenous GR, was transfected with the IL-5 promoter-driven reporter gene construct in the presence or absence of a GATA-3 expression vector. There was no IL-5 promoter activity in the absence of GATA-3 and when GATA-3 is overexpressed, CpdA is able to further induce the activity of cAMP-stimulated GATA-3, confirming that the IL5 promoter is induced by a CpdA-modulated GATA-3 activity (Fig. 6C).

Next, we analyzed whether the transcriptional activation of CpdA could also be reflected in an increase of IL-5 protein production in purified CD4+ $\mathrm{T}$ cell cultures. Indeed, Fig. 6D shows that CpdA strongly induces IL-5 production. Similar results were obtained in non-adherent and in total splenocyte cultures (data not shown).

\section{Discussion}

In this work we describe the mechanisms of action following selective GR modulation in immune T cells. Hereto, we studied the effect of CpdA, as a paradigm for a dissociative GR activity, on the activity of key Th TFs that control the development and final outcome of the adaptive immune responses: T-bet, involved in Th1 cellular immunity; and GATA-3, involved in Th2 humoral immune responses.

Our findings demonstrate that in $\mathrm{T}$ cell lines, CpdA inhibits the transcriptional activity of T-bet via a mechanism involving GRmediated transrepression, similar to the effect previously described for GCs [26]. On the other hand, different from the mechanism that was previously described for GCs on GATA-3 activity [27], CpdA induces the transcriptional activity of GATA-3 via an enhanced induction of p38 MAPK-mediated GATA-3 phosphorylation and subsequent nuclear translocation. Considering that in rats with experimental autoimmune neuritis, CpdA treatment increased the numbers of anti-inflammatory M2 macrophages and inhibited the mRNA expression of inflammatory cytokines [8], CpdA may have a dual effect on immune cells: 1) on macrophages to dampen an uncontrolled first line of defense, and 2) modulation of the Th1-Th2 balance in the second stage.

Since nothing is known yet about the regulation of key Th immune-regulatory TFs, we first investigated the role of CpdA on the transcriptional activity of T-bet in T cells. We transfected EL4 cells with a construct bearing T-bet response elements cloned upstream of the luciferase gene and found that CpdA strongly inhibits the transcriptional activity of T-bet. The actions of CpdA were reverted by the synthetic antagonist RU38486 which acts as a competitor for ligand binding to GR, unambiguously demonstrating direct GR involvement.

It is generally accepted that DNA binding and subsequent activation of gene expression requires the dimerization of GR and 

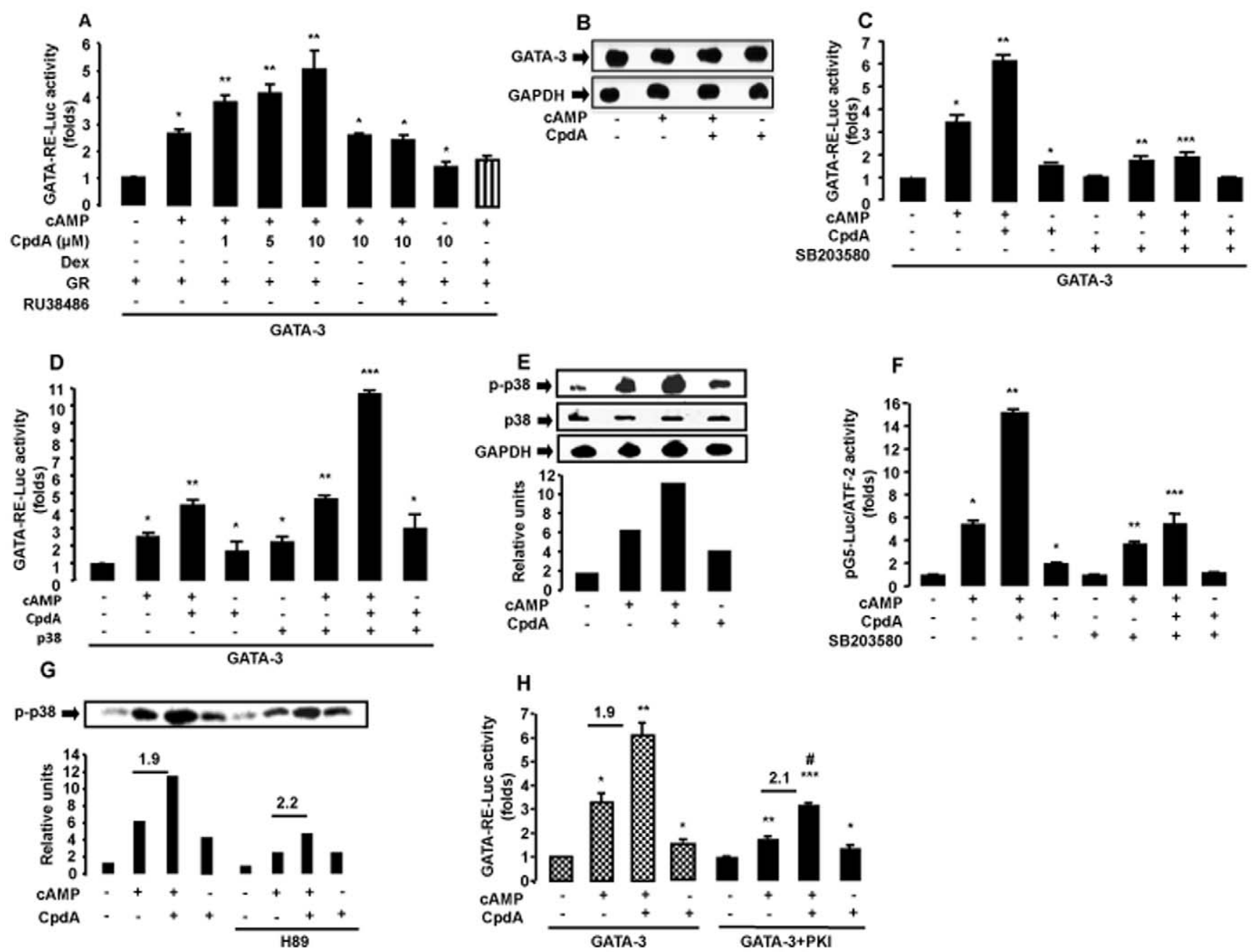

Figure 4. Compound A induces GATA-3 transcriptional activity by signaling through p38 MAPK. $A$, EL4 cells were transfected with $9 \mu \mathrm{g}$ of a reporter plasmid, which contains GATA-3 response elements upstream of the luciferase gene (GATA-RE-Luc) and with $9 \mu \mathrm{g}$ of GATA-3 and GR expression vectors. After $16 \mathrm{~h}$, cells were stimulated for $5 \mathrm{~h}$ with Compound $\mathrm{A}(\mathrm{CpdA}, 1,5$ and $10 \mu \mathrm{M})$, Dexamethasone (Dex, $10 \mathrm{nM})$, cAMP (0.3 mM) and with the GR specific antagonist RU38486 $(1 \mu \mathrm{M}) . n=6,{ }^{*} p<0.001$ vs. GATA-3 without CpdA and cAMP, ${ }^{* *} p<0.001$ vs. GATA-3 with cAMP and without CpdA. B, Lysates obtained from transfection experiments performed under similar conditions as mentioned above, were analysed by Western Blot. GAPDH was used as loading control. C, EL4 cells were transfected with $9 \mu \mathrm{g}$ of GATA-RE-Luc reporter and with $9 \mu \mathrm{g}$ of GATA-3 and GR expression vectors. After $16 \mathrm{~h}$, cells were stimulated for $5 \mathrm{~h}$ with CpdA $(10 \mu \mathrm{M})$ and cAMP. Also, EL4 cells were pretreated during $1 \mathrm{~h}$ with the p38 MAPK inhibitor, SB203580 $(10 \mu \mathrm{M}) . \mathrm{n}=6,{ }^{*} \mathrm{p}<0.001$ vs. GATA-3 without CAMP and CpdA, ${ }^{* *} \mathrm{p}<0.001$ vs. GATA-3 with cAMP and without CpdA, *** $\mathrm{p}<0.001$ vs. GATA-3 with cAMP and CpdA. D, EL4 cells were transfected with $9 \mu \mathrm{g}$ of GATA-RE-Luc reporter and $9 \mu \mathrm{g}$ of GATA-3, GR and p38 MAPK expression vectors. After $16 \mathrm{~h}$, cells were stimulated for $5 \mathrm{~h}$ with CpdA and cAMP. $n=6,{ }^{*} p<0.001$ vs. GATA-3 without cAMP and CpdA, ${ }^{* *}$ $\mathrm{p}<0.001$ vs. GATA-3 with cAMP and without CpdA, ${ }^{* * *} \mathrm{p}<0.001$ vs. GATA-3 with cAMP and p38. E, EL4 cells were transfected with $20 \mu \mathrm{g}$ of the GR expression vector. After $16 \mathrm{~h}$, EL4 cells were pretreated during 30 minutes with CpdA and then with cAMP during 25 minutes. Cell lysates were prepared for Western Blot analysis against phospho-p38 (p-p38) MAPK. GAPDH and total p38 signals were used as loading controls. Lower panel: NIH Image semiquantification. $F$, EL4 cells were transfected with $9 \mu \mathrm{g}$ of pFA-ATF2 and $9 \mu \mathrm{g}$ of pG5-Luc reporter plasmid, and the GR expression vector. After $16 \mathrm{~h}$, cells were stimulated for $5 \mathrm{~h}$ with CpdA and cAMP. Also, EL4 cells were pretreated during $1 \mathrm{~h}$ with the p38 MAPK inhibitor, SB203580. $\mathrm{n}=$ $6,{ }^{*} p<0.001$ vs. basal without cAMP and CpdA, ${ }^{* *} p<0.001$ vs. CAMP without CpdA, ${ }^{* * *} p<0.001$ vs. cAMP and CpdA. For all the transfections experiments, results, as folds, normalized to $\beta$-galactosidase activity, are expressed as mean \pm SEM, averaged from three independent experiments. doi:10.1371/journal.pone.0035155.g004

binding to a palindromic GRE [33]. Mutagenesis studies of the GR DBD showed that disruption of the D-loop abolishes the ability of GR to dimerize, thus inhibiting GC-mediated activation [34]. On the other hand, a GR mutant harboring a point mutation in the second zinc finger of the DBD was unable to repress stimulated NF- $\kappa \mathrm{B}$ but still could activate target genes through GREs suggesting that activation and transrepression are separate phenomena. As mentioned before, S425G DBD mutant has a serine to glycine substitution at position 425 , which removes a hydroxyl group supposed to alter bondings between the zinc finger domain and other proteins such as T-bet [26]. Our finding that the first zinc finger of the DBD is important for CpdA and GCmediated inhibition of T-bet activity strongly suggests that this region is essential for transrepression between the GR and T-bet.

IFN- $\gamma$ is a strong activator of inflammatory responses and cellular immunity. Studies of the IFN- $\gamma$ gene promoter have shown that T-bet elements play an important role in the induction of transcription and production of this cytokine [21,24,35,36]. It has been previously reported that CpdA inhibits IFN- $\gamma$ mRNA expression and cytokine production in spinal cord and total 
A

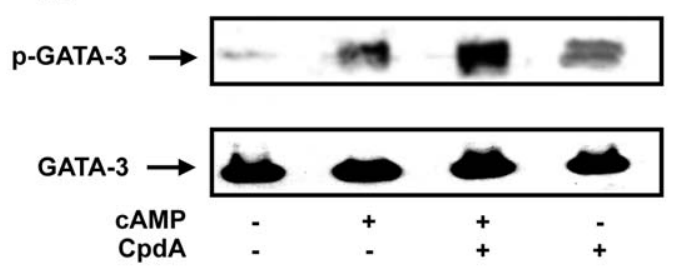

B

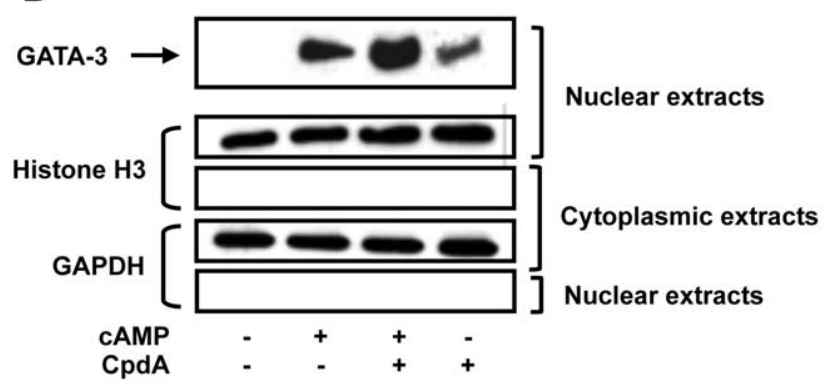

Figure 5. Compound $A$ induces GATA-3 phosphorylation and nuclear translocation. $A$, EL4 cells were transfected with $15 \mu \mathrm{g}$ of the $\mathrm{GR}$ and $15 \mu \mathrm{g}$ of GATA-3 expression vectors. After $16 \mathrm{~h}$ in culture, EL4 cells were pretreated during 30 minutes with or without Compound $A$ $(\mathrm{CpdA}, 10 \mu \mathrm{M})$ and then treated under basal or activated conditions using CAMP $(0.3 \mathrm{mM})$ during 25 minutes. Cell lysates were prepared for Western Blot analysis against phospho-GATA-3 (p-GATA-3) (bands of $55 \mathrm{kDa}$ ). Total GATA-3 signal was used as loading control. One out of three independent experiments with similar results are shown. B, EL4 cells were transfected with $15 \mu \mathrm{g}$ of the GR and $15 \mu \mathrm{g}$ of GATA-3 expression vectors. After $16 \mathrm{~h}$ in culture, EL4 cells were pretreated during 30 minutes with or without $\mathrm{CpdA}(10 \mu \mathrm{M})$ and then treated under basal or activated conditions using CAMP $(0.3 \mathrm{mM})$ during 25 minutes. Cell nuclear and cytoplamic extracts were prepared for GATA-3 analysis by Western Blot. Histone H3 and GAPDH signals were used as nuclear and cytoplasmic extracts control respectively. One out of three independent experiments with similar results are shown.

doi:10.1371/journal.pone.0035155.g005

splenocytes from mice with EAE [9] and also the mRNA expression in lymph nodes of rats with EAN [8]. Our data add onto these observations by demonstrating the inhibitory effect of CpdA on PMA and Ionomycin-stimulated IFN- $\gamma$ production in purified CD4+ T cells. Moreover, we continue to show that the underlying molecular mechanism of IFN- $\gamma$ gene inhibition following selective GR modulation involves the inhibition of Tbet activity. Considering the previously reported inhibition of NF$\kappa \mathrm{B}$ by CpdA [4], we speculate that other TFs besides T-bet, such as NF- $\mathrm{BB}$, may also be involved and may contribute to the inhibition of IFN- $\gamma$ cytokine production by CpdA. If we consider that IFN- $\gamma$ is a major activator of macrophages and that CpdA inhibits IFN- $\gamma$ production by $\mathrm{T}$ cells, the inhibitory effect of CpdA on macrophage-mediated inflammatory responses may be reinforced by the inhibition of IFN- $\gamma$ production and therefore may further favor the resolution of inflammation.

Upon investigating the effect and functional consequences of CpdA on the activity of the Th2 key TF GATA-3 we found that CpdA induces GATA-3 activity on its own GATA-3 response elements. GR specificity was guaranteed by showing that the CpdA effect could be reversed by the synthetic antagonist RU38486 that acts as a competitor for binding to GR.

GCs inhibit GATA-3 activity by inhibition of p38 MAPKmediated GATA-3 phosphorylation and hindering its nuclear translocation $[27,28]$. Bearing this in mind, we studied the effect of
CpdA on p38 MAPK signaling and its subsequent effect on GATA-3 activity. Using the p38 MAPK inhibitor SB203580, we showed that CpdA induces GATA-3 transcriptional activity by induction of p38 MAPK phosphorylation. Intracellular increments of cAMP levels are associated with an augmentation of Th2 cytokine production via GATA-3 and PKA activation [20]. Therefore we performed transfection and Western Blot experiments using the heat stable inhibitor of the PKA (PKI) or the PKA inhibitor H89 and demonstrated that CpdA induces GATA-3 activity independently of PKA (data not shown). CpdA induction of p38 MAPK phosphorylation is mediated by the GR because pre-incubation with RU38486 reversed this effect (data not shown). In addition, Western Blot experiments using a specific antibody against phosphorylated GATA-3 show that CpdA strongly induces GATA-3 phosphorylation.

GCs induce the expression of mitogen-activated protein kinase (MAPK) phosphatase-1 (MKP-1), the endogenous inhibitor of p38 MAPK, which is necessary for GATA-3 nuclear translocation $[27,28]$. To study whether the induction of p38 MAPK by CpdA could be due to the inhibition of MKP-1 expression, we checked the levels of endogenous MKP-1. These experiments however showed that MKP-1 protein levels are not affected by CpdA (data not shown). This is in accordance with previous results showing that MKP-1 expression on primary microglia and astrocytes is not affected by the addition of CpdA [9]. We also tested the possibility that the mitogen- and stress-activated protein kinase- 1 (MSK1), which has been shown to be activated by p38 MAPK and inhibited by GC [37], was implicated in CpdA induction of GATA-3 phosphorylation. However, no MSK1 induction was found in CpdA-stimulated EL4 cells (data not shown).

Because GATA-3 directly controls the expression of IL-5 gene, by binding to elements on the -70 to -59 region [38] on its minimal promoter, we used as a readout of CpdA effect on GATA-3 activity the IL-5 promoter. We describe for the first time that selective modulation of GR, by means of the transrepressionfavouring GR modulator CpdA, strongly induces IL-5 gene and cytokine production via an enhancement of the activation of GATA-3. We show that CpdA induces GATA-3 activity, driving the IL-5 promoter. The addition of SB203580 inhibits this induction, again suggesting an involvement of the p38 MAPK pathway. GATA-3 binding site mutations in the IL-5 promoter further confirm that GATA-3 is a likely target of CpdA, and is needed in order to enhance the activity of this promoter. The mechanism described here does not rule out that in a full physiological promoter context additional indirect effects may occur. For example, a combination of CpdA-mediated induction of other kinase pathways implicated in GATA-3 phosphorylation or in p38 MAPK induction such as the upstream MAPK kinases MKK3 and MKK6 [39], an interaction with other TFs involved in the transcriptional complex of GATA-3, a recruitment and activation of other TFs to the IL-5 promoter [40] or even a recruitment of co-activators by GR may all contribute to the overall induction of IL-5 gene.

In lymph nodes of rats with EAN, CpdA inhibits mRNA expression of the IFN- $\gamma$ gene and at the same time induces Th2type cytokines expression [8]. In line with this observation, our data showing that CpdA inhibits T-bet activity which impacts on IFN- $\gamma$ gene, and at the same time induces GATA- 3 mediated Th2-type cytokine production, may contribute to provide a molecular understanding for the previously described immunosuppressive action of CpdA in EAN.

Summing up, CpdA directly inhibits T-bet activity and IFN- $\gamma$ production. On the other hand, considering the mutual inhibitory action between T-bet and GATA-3 [14,17,25,41], the inhibition 

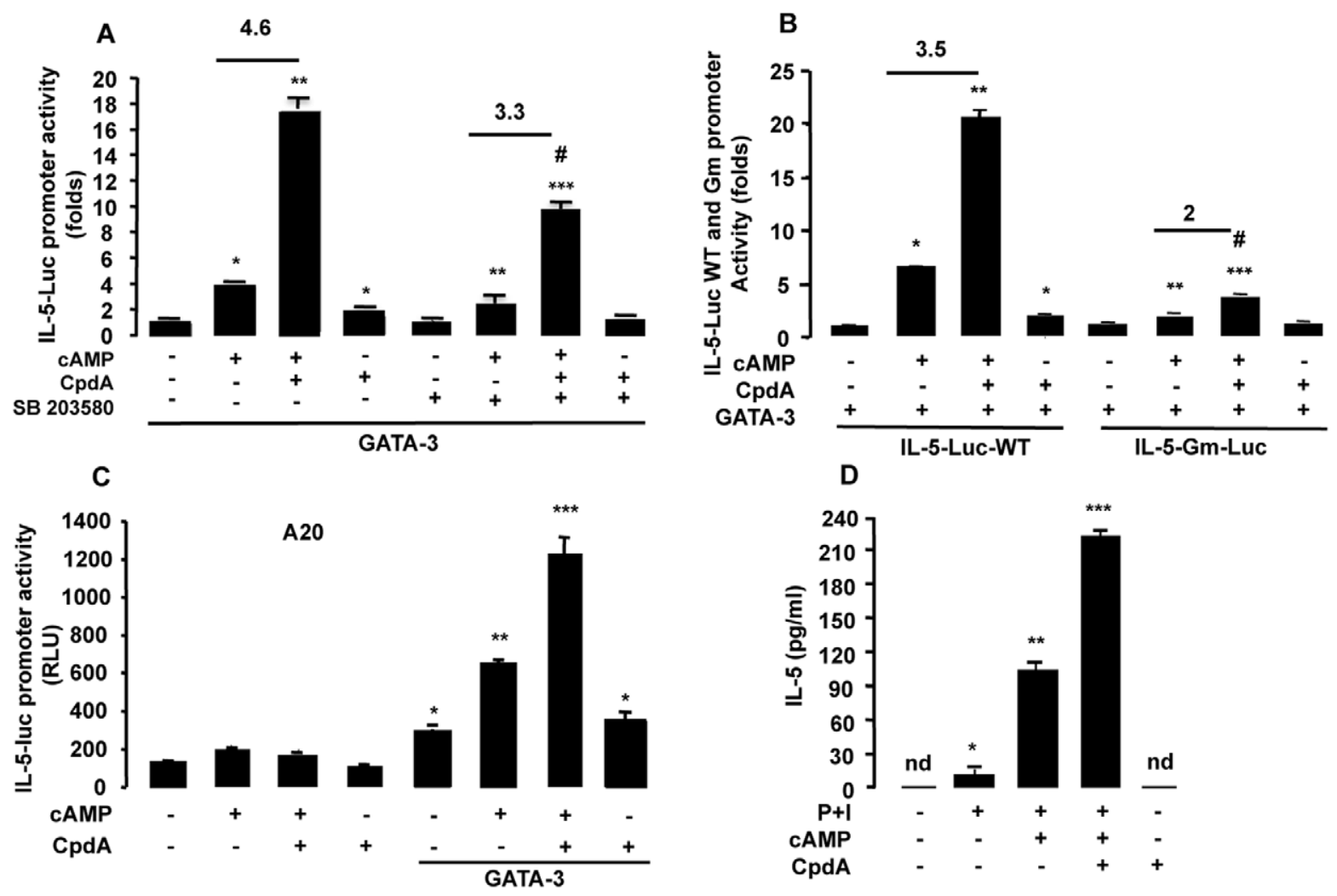

Figure 6. Compound $\mathbf{A}$ inhibits IL-5 promoter activity and cytokine production. A, EL4 cells were cotransfected with $9 \mu \mathrm{g}$ of IL-5-LuC reporter plasmid plus $9 \mu \mathrm{g}$ of GR and GATA-3 expression vectors. After $16 \mathrm{~h}$, cells were stimulated for $5 \mathrm{~h}$ with CpdA (10 $\mu$ M) and cAMP. Also, EL4 cells were pretreated during $1 \mathrm{~h}$ with $\mathrm{p} 38$ inhibitor, SB203580 $(10 \mu \mathrm{M}) . \mathrm{n}=6,{ }^{*} \mathrm{p}<0.001$ vs. GATA-3 without cAMP and CpdA, ${ }^{* *} p<0.001$ vs. GATA-3 with cAMP and without $\mathrm{CpdA}$, *** $\mathrm{p}<0.001$ vs. GATA-3 with cAMP and CpdA, \# $\mathrm{p}<0.001$ vs. GATA-3 with cAMP and SB203580 and without CpdA. B, EL4 cells were cotransfected with $9 \mu \mathrm{g}$ of the wild-type or GATA-3 mutated-binding site on the IL-5 promoter (IL-5-Luc-WT and IL-5-Gm-Luc) plus $9 \mu \mathrm{g}$ of GR and GATA-3 expression vectors. After $16 \mathrm{~h}$, cells were stimulated for $5 \mathrm{~h}$ with CpdA and cAMP. $\mathrm{n}=6$, * $\mathrm{p}<0.001$ vs. GATA-3 without cAMP and CpdA on IL-5-Luc WT, ${ }^{* *} p<0.001$ vs. GATA-3 with cAMP and without CpdA on IL-5-Luc WT, ${ }^{* * *} p<0.001$ vs. GATA-3 with cAMP and CpdA on IL-5Luc WT, \# $p<0.05$ vs. GATA-3 with cAMP and without CpdA on IL-5-Gm-Luc. C, A20 cells were cotransfected with $9 \mu \mathrm{g}$ of IL-5-Luc reporter plus $9 \mu \mathrm{g}$ of GR and GATA-3 expression vectors. After $16 \mathrm{~h}$, cells were stimulated for $5 \mathrm{~h}$ with CpdA and cAMP. $n=6,{ }^{*} p<0.001$ vs. basal, ${ }^{* *} \mathrm{p}<0.001$ vs. GATA$3,{ }^{* * *} p<0.001$ vs GATA-3 with cAMP. D, Purification of T cells was achieved as described in Materials and Methods. Cells were activated with PMA (P), lonomycin (I) and CAMP during $24 \mathrm{~h}$ and then with CpdA for $5 \mathrm{~h}$. Supernatants were used to measure mouse IL-5 by ELISA. $\mathrm{n}=4$, * $\mathrm{p}<0.05$ vs. basal without $\mathrm{P}+\mathrm{l},{ }^{* *} \mathrm{p}<0.001$ vs. $\mathrm{P}+\mathrm{I}$ without $\mathrm{CAMP},{ }^{* * *} \mathrm{p}<0.001$ vs. $\mathrm{P}+\mathrm{l}$ and $\mathrm{CAMP}$, of one representative experiment of three independent experiments with similar results. For the transfections experiments, results, as folds, normalized to $\beta$-galactosidase activity, are expressed as mean \pm SEM, averaged from three independent experiments.

doi:10.1371/journal.pone.0035155.g006

of the Thl profile by CpdA may be reinforced by inducing GATA-3 and Th2-type cytokine production, which in turn may further inhibit Thl development. T-bet is known for its important role in inflammation and autoimmune disorders such as Inflammatory Bowel Disease, Multiple Sclerosis, Inflammatory Arthritis and Diabetes [42]. Therefore, CpdA-mediated inhibition of the Thl phenotype may be helpful to understand the antiinflammatory role reported for CpdA in many of these diseases and holds potential for the application of novel drugs which retain CpdA-like characteristics in other inflammatory and Th1mediated autoimmune disorders. Indeed, although CpdA is not druggable as such, its molecular regulation of GR activities presents important insights on GR biology in immune regulation, and confidence that the dissociative ligand hypothesis remains of great value. However a clinical application of CpdA-like molecules for the treatment of inflammatory and Th1-mediated autoimmune diseases must be carefully studied taking into account the association of GATA-3 and IL-5 with allergic diseases such as asthma pathogenesis. Therefore, a balance considering the reduction of T-bet-mediated autoimmune and inflammatory responses together with the induction of Th2 responses should be considered while setting up the clinical use of GR-ligands that harbor similar characteristics as CpdA.

\section{Materials and Methods}

\section{Splenocytes and Cell Line Cultures}

Studies employing animals were conducted according to the NIH guidelines and were approved by the Animal Research and Care Committee (CICUAL \# 2009/044) at the School of Exact and Natural Sciences, University of Buenos Aires.

Spleens were removed aseptically from naive BALBc mice and dispensed through a metal mesh in order to obtain single-cell suspensions. Splenocytes were resuspended at a density of $2.5 \times$ $10^{6}$ cells and plated in 6-well plates. Purification of T cells was achieved as described [26,27] using a nylon wool column. Monocyte contamination was verified to be less than $1 \%$. Purity of the cell population was assayed by immunofluorescence using specific monoclonal antibodies (Serotech Laboratories Limited, Toronto, Canada) [26]: CD2, CD4, CD8, CD14, CD19, and 
CD45, which define antigens on T cells/NK cells, Th lymphocytes, T cytotoxic/suppressor cells, monocytes/macrophages, B cells and leukocytes (leukocyte common antigen), respectively. Where indicated, these purified murine $\mathrm{T}$ cells were further purified by FACS (FACSAriaII, Becton Dickinson, San Jose CA) using anti-CD4 antibody (BD Pharmingen, San Jose, CA) to 95$99 \%$ of purity. To determine cytokine secretion cells were seeded and stimulated at the beginning of the culture with $10 \mathrm{ng} / \mathrm{ml}$ PMA, $500 \mathrm{ng} / \mathrm{ml}$ ionomycin (I) for $24 \mathrm{~h}$ and then incubated with $10 \mu \mathrm{M}$ CpdA for 6,12 or $24 \mathrm{~h}$. Cytokines were measured according to the manufacturer's instructions by ELISA (Pierce Biotechnology Inc. Rockford, IL).

The murine cell line EL4, extensively used for studies with these Th TFs $[20,26,27,43]$ was obtained from Dr. N.W. Zwirner (Department of Microbiology, Parasitology and Immunology, School of Medicine, University of Buenos Aires, Buenos Aires, Argentina) and were treated, where indicated, with $10-100 \mathrm{nM}$ Dex (a synthetic GC) or $0.1-10 \mu \mathrm{M}$ CpdA and $10 \mathrm{ng} / \mathrm{ml}$ PMA, $500 \mathrm{ng} / \mathrm{ml} \mathrm{I}$, and/or $0.3 \mathrm{mM}$ cAMP (all, except CpdA, from Sigma Chemical Co., St. Louis, MO). Transfection experiments were also repeated in human Jurkat T cells and the A20 mouse B lymphoma cell line, both obtained from Dr. Mirta Giordano (Department of Immunology, Institute for Hematologic Research, National Academy of Medicine, Buenos Aires, Argentina).

CpdA was synthesized as described by Louw et al. [44]. CpdA was lyophilized and stored at $-70^{\circ} \mathrm{C}$.

Some experiments were performed in the presence of the specific GR antagonist RU38486 (Sigma Chemical Co., St. Louis, MO) $(1 \mu \mathrm{M})$, added 30 minutes before the addition of GCs, to prove ligand-specific interactions with the ligand-binding domain of GR.

For analysis of MAPK activation, cells were incubated with or without the PKA inhibitor H89, the p38 inhibitor SB203580, the MEK-1 inhibitor PD98059 and c-Jun NH2-terminal kinase (JNK) inhibitor SP600125 (10, 20 and $40 \mu \mathrm{M}$ ) (Calbiochem, San Diego, CA) for $1 \mathrm{~h}$ before stimulating with cAMP.

\section{Plasmids and transfection assays}

The plasmid constructs were kindly provided and previously described as follows: the murine IL-5 promoter (which contains the -1200 to +33 sequence from the IL-5 gene) coupled to the luciferase reporter vector, was provided by Dr. T. Yokota [45] (IL5 -Luc); the murine wild-type IL-5 promoter $(-120$ to +44$)$ and mutated on the GATA-3 binding site, were provided by Dr. E. Serfling [46] (IL-5-Luc-WT and IL-5-Luc-Gm); the murine GATA-3 expression vector, obtained from Dr. J. Leiden [11] (pcDNA3-GATA-3); the reporter gene vector carrying GATA-3 response elements, coupled to the luciferase reporter vector, was provided by Dr. A. Ray [18] (GATA-RE-Luc); the human GR expression vector subcloned in a cytomegalovirus promoter (CMV)-hGR and the CMV- $\beta$-galactosidase were supplied by Dr. D. Spengler [47]; the p38 MAPK expression vector (pcEFLp38), the chimera pG5-Luc/ATF-2 and the catalytic subunit of PKAc was provided by Dr. O. Cosso and Dr. T. Tanos [48,49]; the heat stable inhibitor of the PKA (PKI) was provided by Dr. R. Mauer [50]; the murine IFN- $\gamma$ promoter was provided by Dr. $\mathrm{H}$. S. Fox [51] and was subcloned into the pGL3-Basic luciferase reporter vector (Promega, Madison, WI) [26] (IFN- $\gamma$-Luc); murine pJG4.5mT-bet, obtained from Dr. L. H. Glimcher [21], was subcloned into the pcDNA3 expression vector (Invitrogen, Carlsbad, CA) [26] (pcDNA3-T-bet); the T-bet binding sites [21] subcloned into the pTATA-GL3-Basic luciferase reporter vector (Promega, Madison, WI) was obtained as previously described [26] ((T-bet-RE)3-Luc); the TK-GRE2-Luc promoter, was supplied by Dr. D. Spengler [47]; the wild-type human GR (phGR-SB) and its GR DNA-binding domain (DBD)-derived mutants A458T and S425G, were provided by Dr. A. C.B. Cato [30], the construct containing the multimerized NF- $\kappa \mathrm{B}$-binding sites linked to a minimal promoter upstream of the luciferase gene ( $\mathrm{BB}-$ Luc promoter) was previously described [52].

Transfection of EL4, Jurkat and A20 cells $\left(5 \times 10^{7}\right.$ cells $\left./ \mathrm{ml}\right)$ was performed by electroporation, as previously described [26,27]. Cells were washed with PBS and extracts were prepared with reporter lysis buffer (Promega, Madison, WI). After treatments, cells were harvested and luciferase activity was measured as previously described [26,27], using the Luciferase measure kit (Promega, Madison, WI) with a Junior luminometer (Berlthod, Bad Wildbad, Germany). CMVhGR expression vector was cotransfected in EL4 cells in order to make them responsive to GCs. In all cases, cells were cotransfected with the RSV- $\beta$ galactosidase plasmid expression vector, used as control for transfection efficiency to standardize the results. Lysates from the transfections were also analyzed by Western Blot as described below.

\section{Western Blot Assays}

Following the appropriate inductions, cells were washed once with PBS ( $\mathrm{pH} \mathrm{7.0),} \mathrm{and} \mathrm{lysates} \mathrm{were} \mathrm{prepared} \mathrm{as} \mathrm{previously}$ described [26,27]. The membranes were incubated with the mouse monoclonal anti-GATA-3 antibody (200 ng/ml) (Santa Cruz Biotechnology, Santa Cruz, CA), anti-phospho-GATA-3 antibody (Abcam Inc, Cambridge, UK) (dilution: 1:500), followed by incubation with HRP-conjugated specific secondary antibodies (dilution: 1:3000) (Bio-Rad Laboratories, Hercules, CA), and detection was performed with the ECL kit according to the manufacturer's instruction (Pierce Biotechnology, Rockford, IL). The anti-GAPDH antibody (dilution: 1:10000) (Abcam Inc, Cambridge, UK) was routinely used as a loading control. Antihistone H3 antibody (dilution: 1:20000) (Millipore, Billerica, MA) was used as a control for the efficiency of the nuclear fractionation and the anti-GAPDH antibody (dilution: 1:10000) (Abcam Inc, Cambridge, UK) as a cytoplasmic fractionation control. To separate nuclei from cytoplasm, we proceeded as previously described [27]. To separate nuclei from cytoplasm, $1 \times 10^{7}$ cells were washed in ice-cold phosphate-buffered saline and incubated for $10 \mathrm{~min}$ on ice in $200 \mu \mathrm{l}$ of buffer A containing $10 \mathrm{mM}$ HEPES, pH 7.9, $1.5 \mathrm{mM} \mathrm{MgCl}_{2}, 10 \mathrm{mM} \mathrm{KCl}, 1 \mathrm{mM}$ dithiothreitol, $2 \mathrm{mM}$ orthovanadate, $0.5 \mathrm{mM}$ phenylmethylsulfonyl fluoride and protease inhibitor cocktail (Roche Diagnostics, Mannheim, Germany). At the end of the incubation, a 0.1 volume of $1 \%$ Nonidet P-40 was added and lysates were centrifuged at $3000 \mathrm{xg}$ for $5 \mathrm{~min}$. Supernatants were collected and used as cytoplasmic extract. Pelleted nuclei were resuspended in $50 \mu \mathrm{l}$ of lysis buffer containing $20 \mathrm{mM}$ HEPES, $\mathrm{pH}$ 7.9, 25\% v/v glycerol,

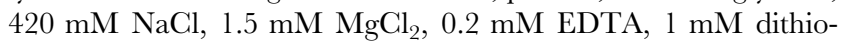
threitol, $2 \mathrm{mM}$ orthovanadate, $0.5 \mathrm{mM}$ phenylmethylsulfonyl fluoride and protease inhibitor cocktail (Roche Diagnostics, Mannheim, Germany). After incubation for $30 \mathrm{~min}$ at $4^{\circ} \mathrm{C}$ with vigorous shaking, nuclei were centrifuged at $12000 \mathrm{xg}$ for $10 \mathrm{~min}$ and the supernatants were collected and used as nuclear extract.

To analyze MAPK activation, blots were incubated with rabbit anti-phospho-p38 (p-p38) (Thr180/Tyr182) and rabbit anti-panp38 antibodies (dilution: 1:1000) (Cell Signaling, Beverly, MA).

\section{Statistics}

Statistics were performed by ANOVA in combination with the Scheffés test. Data are shown as mean \pm SEM. 


\section{Acknowledgments}

We thank Dr. E. Serfling, Dr. D. Spengler, Dr. S. Szabo, Dr. S. Cao, Dr. L. Glimcher, Dr. H. S. Fox, Dr. A. Ray, Dr. J. Leiden, Dr R. Mauer, Dr. M. Bell, Dr. T. Yokota, Dr. A. C.B. Cato, Dr. T. Tanos and Dr. O. Cosso for providing the plasmids used in this work.

\section{References}

1. Kleiman A, Tuckermann JP (2007) Glucocorticoid receptor action in beneficial and side effects of steroid therapy: lessons from conditional knockout mice. Mol Cell Endocrinol 275: 98-108.

2. Reichardt HM, Tuckermann JP, Gottlicher M, Vujic M, Weih F, et al. (2001) Repression of inflammatory responses in the absence of DNA binding by the glucocorticoid receptor. EMBO J 20: 7168-7173.

3. De Bosscher K, Haegeman G, Elewaut D (2010) Targeting inflammation using selective glucocorticoid receptor modulators. Curr Opin Pharmacol 10: 497-504.

4. De Bosscher K, Vanden Berghe W, Beck IM, Van Molle W, Hennuyer N, et al. (2005) A fully dissociated compound of plant origin for inflammatory gene repression. Proc Natl Acad Sci USA 102: 15827-15832.

5. Robertson S, Allie-Reid F, Vanden Berghe W, Visser K, Binder A, et al. (2010) Abrogation of glucocorticoid receptor dimerization correlates with dissociated glucocorticoid behavior of compound a. J Biol Chem 285: 8061-8075.

6. Dewint P, Gossye V, De Bosscher K, Vanden Berghe W, Van Beneden K, et al. (2008) A plant-derived ligand favoring monomeric glucocorticoid receptor conformation with impaired transactivation potential attenuates collageninduced arthritis. J Immunol 180: 2608-2615.

7. Wust S, Tischner D, John M, Tuckermann JP, Menzfeld C, et al. (2009) Therapeutic and adverse effects of a non-steroidal glucocorticoid receptor ligand in a mouse model of multiple sclerosis. PLoS One 4: e8202.

8. Zhang Z, Zhang ZY, Schluesener HJ (2009) Compound A, a plant origin ligand of glucocorticoid receptors, increases regulatory T cells and M2 macrophages to attenuate experimental autoimmune neuritis with reduced side effects. J Immunol 183: 3081-3091.

9. van Loo G, Sze M, Bougarne N, Praet J, Mc Guire C, et al. (2010) Antiinflammatory properties of a plant-derived nonsteroidal, dissociated glucocorticoid receptor modulator in experimental autoimmune encephalomyelitis. Mol Endocrinol 24: 310-322.

10. Rauch A, Gossye V, Bracke D, Gevaert E, Jacques P, et al. (2011) An antiinflammatory selective glucocorticoid receptor modulator preserves osteoblast differentiation. FASEB J 25: 1323-1332.

11. Ho IC, Vorhees P, Marin N, Oakley BK, Tsai SF, et al. (1991) Human GATA3: a lineage-restricted transcription factor that regulates the expression of the $\mathrm{T}$ cell receptor alpha gene. EMBO J 10: 1187-1192.

12. Ouyang W, Lohning M, Gao Z, Assenmacher M, Ranganath S, et al. (2000) Stat6-independent GATA-3 autoactivation directs IL-4-independent Th2 development and commitment. Immunity 12: 27-37.

13. Mosmann TR, Sad S (1996) The expanding universe of T-cell subsets: Th1, Th2 and more. Immunol Today 17: 138-146.

14. Nawijn MC, Dingjan GM, Ferreira R, Lambrecht BN, Karis A, et al. (2001) Enforced expression of GATA-3 in transgenic mice inhibits Th1 differentiation and induces the formation of a T1/ST2-expressing Th2-committed $\mathrm{T}$ cell compartment in vivo. J Immunol 167: 724-732.

15. Takemoto N, Kamogawa Y, Jun Lee H, Kurata H, Arai KI, et al. (2000) Cutting edge: chromatin remodeling at the IL-4/IL-13 intergenic regulatory region for Th2-specific cytokine gene cluster. J Immunol 165: 6687-6691.

16. Zhu J, Yamane H, Cote-Sierra J, Guo L, Paul WE (2006) GATA-3 promotes Th2 responses through three different mechanisms: induction of Th2 cytokine production, selective growth of Th2 cells and inhibition of Th1 cell-specific factors. Cell Res 16: 3-10.

17. Zhou M, Ouyang W (2003) The function role of GATA-3 in Th1 and Th2 differentiation. Immunol Res 28: 25-37.

18. Chen CH, Zhang DH, LaPorte JM, Ray A (2000) Cyclic AMP activates p38 mitogen-activated protein kinase in Th2 cells: phosphorylation of GATA-3 and stimulation of Th2 cytokine gene expression. J Immunol 165: 5597-5605.

19. Maneechotesuwan K, Xin Y, Ito K, Jazrawi E, Lee KY, et al. (2007) Regulation of Th2 cytokine genes by p38 MAPK-mediated phosphorylation of GATA-3. J Immunol 178: 2491-2498.

20. Klein-Hessling S, Jha MK, Santner-Nanan B, Berberich-Siebelt F, Baumruker T, et al. (2003) Protein kinase A regulates GATA-3-dependent activation of IL-5 gene expression in Th2 cells. J Immunol 170: 2956-2961.

21. Szabo SJ, Kim ST, Costa GL, Zhang X, Fathman CG, et al. (2000) A novel transcription factor, T-bet, directs Th1 lineage commitment. Cell 100: 655-669.

22. Abbas AK, Murphy KM, Sher A (1996) Functional diversity of helper T lymphocytes. Nature 383: 787-793.

23. Mosmann TR, Coffman RL (1989) TH1 and TH2 cells: different patterns of lymphokine secretion lead to different functional properties. Annu Rev Immunol 7: $145-173$.

\section{Author Contributions}

Conceived and designed the experiments: ACL MAN VFP JPN CG JD FH MJP SG KDB GH EA. Performed the experiments: ACL MAN VFP CG JD SG KDB. Analyzed the data: ACL MAN VFP JPN CG JD FH MJP SG KDB GH EA. Contributed reagents/materials/analysis tools: ACL MAN VFP JPN CG JD FH MJP SG KDB GH EA. Wrote the paper: ACL MAN MJP SG KDB EA.

24. Neurath MF, Weigmann B, Finotto S, Glickman J, Nieuwenhuis E, et al. (2002) The transcription factor $\mathrm{T}$-bet regulates mucosal $\mathrm{T}$ cell activation in experimental colitis and Crohn's disease. J Exp Med 195: 1129-1143.

25. Hwang ES, Szabo SJ, Schwartzberg PL, Glimcher LH (2005) T helper cell fate specified by kinase-mediated interaction of T-bet with GATA-3. Science 307: 430-433.

26. Liberman AC, Refojo D, Druker J, Toscano M, Rein T, et al. (2007) The activated glucocorticoid receptor inhibits the transcription factor T-bet by direct protein-protein interaction. FASEB J 21: 1177-1188.

27. Liberman AC, Druker J, Refojo D, Holsboer F, Arzt E (2009) Glucocorticoids inhibit GATA-3 phosphorylation and activity in T cells. FASEB J 23: $1558-1571$.

28. Maneechotesuwan K, Yao X, Ito K, Jazrawi E, Usmani OS, et al. (2009) Suppression of GATA-3 nuclear import and phosphorylation: a novel mechanism of corticosteroid action in allergic disease. PLoS Med 6: e1000076.

29. Liberman AC, Druker J, Perone MJ, Arzt E (2007) Glucocorticoids in the regulation of transcription factors that control cytokine synthesis. Cytokine Growth Factor Rev 18: 45-56.

30. Heck S, Kullmann M, Gast A, Ponta H, Rahmsdorf HJ, et al. (1994) A distinct modulating domain in glucocorticoid receptor monomers in the repression of activity of the transcription factor AP-1. EMBO J 13: 4087-4095.

31. Tao Y, Williams-Skipp C, Scheinman RI (2001) Mapping of glucocorticoid receptor DNA binding domain surfaces contributing to transrepression of NFkappa B and induction of apoptosis. J Biol Chem 276: 2329-2332.

32. Wang XS, Diener K, Manthey CL, Wang S, Rosenzweig B, et al. (1997) Molecular cloning and characterization of a novel p38 mitogen-activated protein kinase. J Biol Chem 272: 23668-23674.

33. Giguere V, Hollenberg SM, Rosenfeld MG, Evans RM (1986) Functional domains of the human glucocorticoid receptor. Cell 46: 645-652.

34. Reichardt HM, Kaestner KH, Tuckermann J, Kretz O, Wessely O, et al. (1998) DNA binding of the glucocorticoid receptor is not essential for survival. Cell 93: 531-541.

35. Mullen AC, High FA, Hutchins AS, Lee HW, Villarino AV, et al. (2001) Role of T-bet in commitment of TH1 cells before IL-12-dependent selection. Science 292: $1907-1910$

36. Szabo SJ, Sullivan BM, Stemmann C, Satoskar AR, Sleckman BP, et al. (2002) Distinct effects of T-bet in TH1 lineage commitment and IFN-gamma production in CD4 and CD8 T cells. Science 295: 338-342.

37. Beck IM, Vanden Berghe W, Vermeulen L, Bougarne N, Vander Cruyssen B, et al. (2008) Altered subcellular distribution of MSK1 induced by glucocorticoids contributes to NF-kappaB inhibition. EMBO J 27: 1682-1693.

38. Zhang DH, Yang L, Ray A (1998) Differential responsiveness of the IL-5 and IL-4 genes to transcription factor GATA-3. J Immunol 161: 3817-3821.

39. Brancho D, Tanaka N, Jaeschke A, Ventura JJ, Kelkar N, et al. (2003) Mechanism of p38 MAP kinase activation in vivo. Genes Dev 17: 1969-1978.

40. Quan A, McCall MN, Sewell WA (2001) Dexamethasone inhibits the binding of nuclear factors to the IL-5 promoter in human CD4 T cells. J Allergy Clin Immunol 108: 340-348.

41. Usui T, Preiss JC, Kanno Y, Yao ZJ, Bream JH, et al. (2006) T-bet regulates Th1 responses through essential effects on GATA-3 function rather than on IFNG gene acetylation and transcription. J Exp Med 203: 755-766.

42. Peng SL (2006) The T-box transcription factor T-bet in immunity and autoimmunity. Cell Mol Immunol 3: 87-95.

43. Hwang ES, Choi A, Ho IC (2002) Transcriptional regulation of GATA-3 by an intronic regulatory region and fetal liver zinc finger protein 1. J Immunol 169: 248-253.

44. Louw A, Swart P, de Kock SS, van der Merwe KJ (1997) Mechanism for the stabilization in vivo of the aziridine precursor -(4-acetoxyphenyl)-2-chloro-Nmethyl-ethylammonium chloride by serum proteins. Biochem Pharmacol 53: 189-197.

45. Lee HJ, Koyano-Nakagawa N, Naito Y, Nishida J, Arai N, et al. (1993) cAMP activates the IL-5 promoter synergistically with phorbol ester through the signaling pathway involving protein kinase $\mathrm{A}$ in mouse thymoma line EL-4. J Immunol 151: 6135-6142.

46. Klein-Hessling S, Bopp T, Jha MK, Schmidt A, Miyatake S, et al. (2008) Cyclic AMP-induced chromatin changes support the NFATc-mediated recruitment of GATA-3 to the interleukin 5 promoter. J Biol Chem 283: 31030-31037.

47. Rupprecht R, Arriza JL, Spengler D, Reul JM, Evans RM, et al. (1993) Transactivation and synergistic properties of the mineralocorticoid receptor: relationship to the glucocorticoid receptor. Mol Endocrinol 7: 597-603. 
48. Tanos T, Marinissen MJ, Leskow FC, Hochbaum D, Martinetto H, et al. (2005) Phosphorylation of c-Fos by members of the p38 MAPK family. Role in the AP1 response to UV light. J Biol Chem 280: 18842-18852.

49. Blaustein M, Pelisch F, Coso OA, Bissell MJ, Kornblihtt AR, et al. (2004) Mammary epithelial-mesenchymal interaction regulates fibronectin alternative splicing via phosphatidylinositol 3-kinase. J Biol Chem 279: 21029-21037.

50. Day RN, Walder JA, Maurer RA (1989) A protein kinase inhibitor gene reduces both basal and multihormone-stimulated prolactin gene transcription. J Biol Chem 264: 431-436.
51. Fox HS, Bond BL, Parslow TG (1991) Estrogen regulates the IFN-gamma promoter. J Immunol 146: 4362-4367.

52. Plaisance S, Vanden Berghe W, Boone E, Fiers W, Haegeman G (1997) Recombination signal sequence binding protein Jkappa is constitutively bound to the NF-kappaB site of the interleukin- 6 promoter and acts as a negative regulatory factor. Mol Cell Biol 17: 3733-3743. 